Research Paper

\title{
Establishing an Animal Model of Secondary Osteoporosis by Using a Gonadotropin-releasing Hormone Agonist
}

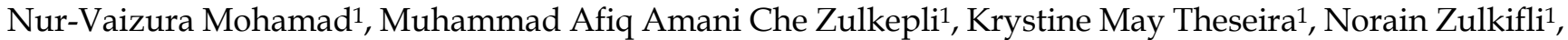
Nur Quraisha Shahrom¹, Nurul Amni Mohamad Ridzuan¹, Nor Aini Jamil2, Ima-Nirwana Soelaiman", Kok-Yong Chin ${ }^{1 凶}$

1. Department of Pharmacology, Faculty of Medicine, Universiti Kebangsaan Malaysia Medical Centre, 56000 Cheras, Kuala Lumpur, Malaysia.

2. School of Healthcare Sciences, Faculty of Health Science, Universiti Kebangsaan Malaysia, 50300 Kuala Lumpur, Malaysia.

$\triangle$ Corresponding author: Tel/Fax: +603-91459573,+603-91459547; Email: chinkokyong@ppukm.ukm.edu.my

(c) Ivyspring International Publisher. This is an open access article distributed under the terms of the Creative Commons Attribution (CC BY-NC) license (https://creativecommons.org/licenses/by-nc/4.0/). See http://ivyspring.com/terms for full terms and conditions.

Received: 2017.09.07; Accepted: 2018.01.07; Published: 2018.01.19

\begin{abstract}
Introduction: Orchidectomy is currently the preferred method to induce bone loss in preclinical male osteoporosis model. Gonadotropin-releasing hormone $(\mathrm{GnRH})$ agonists used in prostate cancer treatment can induce testosterone deficiency but its effects on bone in preclinical male osteoporosis model are less studied.

Objective: This study aimed to evaluate the skeletal effect of buserelin (a GnRH agonist) in male rats and compare it with orchidectomy.

Methods: Forty-six three-month-old male Sprague-Dawley rats were divided into three experimental arms. The baseline arm $(n=6)$ was sacrificed at the onset of the study. In the buserelin arm, the rats received a daily subcutaneous injection of either normal saline $(n=8)$, buserelin acetate at $25 \mu \mathrm{g} / \mathrm{kg}(\mathrm{n}=8)$ or $75 \mu \mathrm{g} / \mathrm{kg}(\mathrm{n}=8)$. In the orchidectomy arm, the rats were either sham-operated $(n=8)$ or orchidectomized $(n=8)$. All groups underwent in-vivo $X$-ray micro-computed tomography scanning at the left proximal tibia every month. Blood was collected at the beginning and the end of the study for testosterone level evaluation. The rats were euthanized after the three-month treatment. The femurs were harvested for biomechanical strength and bone calcium determination.

Results: The results showed that buserelin at both doses caused a significant decline in testosterone level and deterioration in bone microstructure $(p<0.05)$, but did not affect bone calcium content $(p>0.05)$. Buserelin at $25 \mu \mathrm{g} / \mathrm{kg}$ decreased displacement and strain of the femur significantly $(p<0.05)$. Similar changes were observed in the orchidectomized group compared to the sham-operated group but without any significant changes in biomechanical strength $(p>0.05)$.

Conclusion: Buserelin can induce testosterone deficiency and the associated deterioration of bone microarchitecture similar to orchidectomy in three months. However, it may require a longer time to show significant effects on bone strength and mineral content.
\end{abstract}

Key words: androgen; bone; gonadotropin-releasing hormone agonists; male osteoporosis; testosterone

\section{Introduction}

Osteoporosis is a metabolic skeletal disease, characterized by a reduction in bone mass and disruption of microarchitecture, which ultimately results in the loss of bone mechanical strength and increased fragility fracture risk $[1,2]$. The global prevalence of osteoporosis is growing due to the increase in elderly population, especially in the developing countries [3]. Direct and indirect medical expenses associated with fragility fracture is responsible for the increasing healthcare burden of 
osteoporosis worldwide [4]. Although the prevalence of osteoporosis is higher in women, men also suffer from this disease [5]. In fact, $10-15 \%$ of all vertebral fractures and $20-25 \%$ of all hip fractures occur in men [6]. The post-fracture mortality and subsequent fracture risk are consistently higher in men compared to women [7]. Therefore, male osteoporosis is a serious problem deserving more attention.

The primary cause of osteoporosis in men is age-related androgen deficiency [5]. Hypothalamicpituitary-gonadal axis governs androgen production in men. Gonadotropin-releasing hormone $(\mathrm{GnRH})$ is produced pulsatively from the hypothalamic area of the brain to signal the pituitary gland to produce follicle-stimulating hormone (FSH) and luteinizing hormone (LH). The circulating $\mathrm{LH}$ will act on the testes to stimulate the production of androgens. Androgens, i.e. testosterone and dihydrotestosterone, influence bone health in men by binding to the androgen receptors directly or to the oestrogen receptors indirectly via aromatization to oestrogen [8]. They promote the differentiation of osteoblasts and bone formation, as well as suppress the formation of osteoclasts and bone resorption [8]. Male hypogonadism jeopardises bone health because the androgen level is insufficient to maintain skeletal homeostasis. Male hypogonadism can be divided into primary and secondary hypogonadism [9]. Primary hypogonadism is caused by the failure of the testicles to synthesize sufficient androgens. On the other hand, the cause of secondary hypogonadism is extratesticular. For instance, disruption of hypothalamicpituitary axis due to medications or pituitary tumours will cause secondary hypogonadism [10].

Bone loss induced by testosterone deficiency is replicated in animal models to gain insight of the pathogenesis of the disease and to screen for potential therapeutic agents [11]. Primary hypogonadism induced by orchidectomy is currently the preferred method to induce testosterone deficiency in animals [12]. Previous studies showed that orchidectomy decreased bone mineral density and content, as well as disrupted skeletal microarchitecture in rats $[13,14]$. Nevertheless, orchidectomy is an invasive procedure and it is not similar to secondary hypogonadism in men. Medications, such as gonadotropin-releasing hormone (GnRH) agonists commonly used to suppress testosterone production in prostate cancer therapy, can induce secondary hypogonadism in animals. Overstimulation of GnRH receptors on the pituitary gland by GnRH agonists will desensitize them and halt the production of gonadotropins. Testosterone production by the testes ceases without the stimulation from gonadotropins [15]. Thus, GnRH agonists invoke a state of hypogonadotropic hypogonadism [16]. Buserelin is a synthetic analogue of GnRH hormone, with a greater affinity towards GnRH receptor than GnRH [17]. It is commonly used in the treatment of prostate cancers and endometriosis but causes bone loss $[18,19]$. Few studies have been conducted to investigate the effects of GnRH agonists on bone using preclinical models. Prolonged administration of buserelin, a type of GnRH agonist, has been shown to induce osteopenia in female rats by increasing bone resorption, decreasing bone calcium content and bone mineral density [20, 21]. On the other hand, there is a paucity of data on $\mathrm{GnRH}$ agonist-induced bone loss model in male rats.

This study aimed to determine the effects of buserelin on trabecular microstructure, bone calcium content and biomechanical strength in male rats. The effects of buserelin on bone were compared with orchidectomy. This study will validate the use of buserelin as a method to induce bone loss in male rats, and subsequently promote its use as an alternative preclinical model of male osteoporosis, which is associated with secondary hypogonadism due to pituitary disturbance.

\section{Material and methods}

\section{Animals and treatment}

Forty-six three-month-old male Sprague-Dawley rats were procured from the Laboratory Animal Resource Unit of Universiti Kebangsaan Malaysia (Kuala Lumpur, Malaysia). The rats were housed individually in plastic cages at the animal laboratory in the Department of Pharmacology, University Kebangsaan Malaysia (Kuala Lumpur, Malaysia) under standard conditions $\left(27^{\circ} \mathrm{C}\right.$, natural dark-light cycle, tap water and standard rat chow ad libitum). After a week of acclimatization, the rats were randomized into three experimental arms, i.e. baseline $(n=6)$, orchidectomy $(n=16)$ and buserelin $(n=24)$ experiment arms. The baseline rats were sacrificed upon receipt. The orchidectomy experiment arm was divided into sham-operated $(n=8)$ and orchidectomized $(n=8)$ groups. Both testes of the orchidectomized group were removed, while scrotum of the sham group was opened but the testes were retained. Rats in the buserelin arm were divided into three groups ( $\mathrm{n}=8$ per group), namely normal control, $\mathrm{B} 25$ and B75. The B25 and B75 group received a daily subcutaneous injection of buserelin at either $25 \mu \mathrm{g} / \mathrm{kg}$ or $75 \mu \mathrm{g} / \mathrm{kg}$ body weight for three months. The dose of buserelin at $25 \mu \mathrm{g} / \mathrm{kg}$ was based on a previous study conducted in female rats [17]. A higher dose (75 $\mu \mathrm{g} / \mathrm{kg}$ ) was tested in case of incomplete suppression of testosterone production. The normal control group received equivolume of normal saline $(0.9 \%$ sodium 
chloride in double-distilled water) by subcutaneous injection daily. In vivo X-ray micro-computed tomography of the left proximal tibia was performed monthly. Blood collection was performed at the beginning and at the end of the treatment period for the evaluation of circulating testosterone level. The rats were euthanized under anaesthesia after three months and the femurs were harvested for analysis of bone biomechanical strength and calcium content. The experimental protocol was reviewed and approved by Universiti Kebangsaan Malaysia Animal Ethics Committee (Approval Code: FP/FAR/2015/ CHIN/29-JULY/698-JULY-2015-MAY-2017).

\section{Biochemical analysis}

Blood was collected using plain tubes via tail vein at the beginning of the study and cardiac puncture at sacrifice when the rats were under anaesthesia. It was centrifuged at $3000 \mathrm{rpm}$ for 10 minutes to extract the serum, which was then stored at $-70^{\circ} \mathrm{C}$ until analysis. Serum testosterone level was measured using enzyme-linked immunosorbent assay (Fine Biotech, Wuhan, China).

\section{In vivo $X$-ray computed microtomography (micro-CT)}

Monthly X-ray micro-computed tomographic scanning of the rats was performed using the Skyscan 1076 Scanner (Skyscan, Kartuizersweg Kontich, Belgium). The anaesthetized rats were placed in a holder in the supine position. The energy selected for this study was set at $70 \mathrm{KVp}$ and $100 \mu \mathrm{A}$ with medium image resolution to obtain the best contrast between bone and soft tissues. The volume of interest (200 slices) for trabecular bone parameters was selected at the metaphyseal area located $1.5 \mathrm{~mm}$ below the lowest point of the epiphyseal growth plate of proximal tibia extending distally. To determine the cortical bone parameters, 100 slices were analysed at the diaphyseal area located $2.5 \mathrm{~mm}$ from the metaphyseal area.

\section{Bone calcium content}

The left femur cleaned of soft tissues was dried in an oven at $100^{\circ} \mathrm{C}$ for 24 hours. Next, it was ashed at $800^{\circ} \mathrm{C}$ for 12 hours. The end product was weighed and dissolved in three $\mathrm{ml}$ of nitric acid (Fisher Scientific, Hampton, USA). Then, it was diluted with lanthanum chloride (Sigma Aldrich, St. Louis, German). The calcium content of the solution was determined by an atomic absorption spectrophotometer (AA-689, Shimadzu, Kyoto, Japan) at $422.7 \mathrm{~nm}$.

\section{Biomechanical strength}

A precision universal tester (Autograph AG-10kNG, Shimadzu, Kyoto, Japan) with Trapezium $X$ materials testing operation software was used to evaluate the biochemical strength of the right femur. A three-point bending test was conducted on the femur cleaned of soft tissues. It was placed on an aluminium base, with the dorsal proximal femur placed on the one-rounded edge-free notch while the distal diaphysis at the synostosis on the other side. The femur was moistened with phosphate-buffered saline throughout the test. The roller stamp with the tip consisting of axle-led aluminium was driven down at the central femoral diaphysis (speed $5 \mathrm{~mm} / \mathrm{min}$; span length $10 \mathrm{~mm}$ ) until the primary strength of $1 \mathrm{~N}$ was achieved (Figure 1). The study ended automatically once a loss of strength at $20 \mathrm{~N}$ or a linear change of $2 \mathrm{~mm}$ is detected to avoid shattering the femur specimens. The Trapezium $\mathrm{X}$ software was then used to analyse load $(\mathrm{N})$, displacement $(\mathrm{mm})$, stress $\left(\mathrm{N} / \mathrm{mm}^{2}\right)$, strain (\%) and Young Modulus $\left(\mathrm{N} / \mathrm{mm}^{2}\right)$.

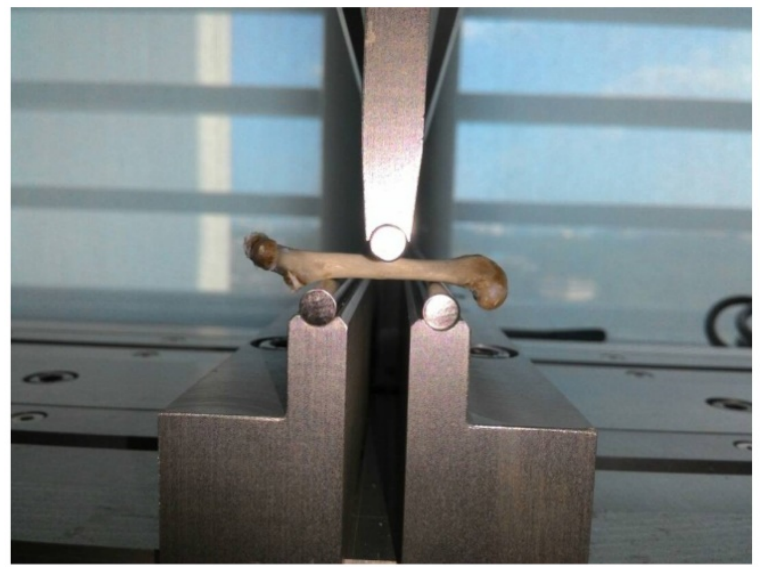

Figure 1. Biomechanical strength test of femur

\section{Statistical analysis}

Shapiro-Wilk test was used to assess the normality of the data. Bone biomechanical strength parameters and calcium content were compared using one-way analysis of variance (ANOVA). Mixed ANOVA was used to analyse the serum testosterone level and trabecular microarchitecture before and after treatment. Pair-wise comparison was performed using suitable post hoc test. Data analysis was done using Statistical Package for Social Sciences (SPSS) version 20.0 (IBM, Armonk, USA). A two-tailed $\mathrm{p}$-value of less than $0.05(\mathrm{p}<0.05)$ was considered statistically significant. All data were presented as mean \pm standard error of the mean.

\section{Results}

All the rats gained weight during the experiment. The percentage of weight gain was significantly higher in the B75 and orchidectomized 
group compared to the $\mathrm{B} 25$ group $(\mathrm{p}<0.05)$. The orchidectomized group also gained more weight compared to the sham-operated group $(\mathrm{p}<0.05)$ (Figure 2).

The baseline testosterone level did not differ significantly among all the study groups $(p>0.05)$. At month 3, testosterone level in the B25, B75 and ORCH group was significantly lower compared to their respective baseline $(p<0.05)$. The testosterone level was also significantly lower in both groups treated with buserelin compared to the normal control $(p<0.05)$. Similarly, the orchidectomized rats had significantly lower testosterone level compared to the sham-operated and B25 group rats $(p<0.05)$.

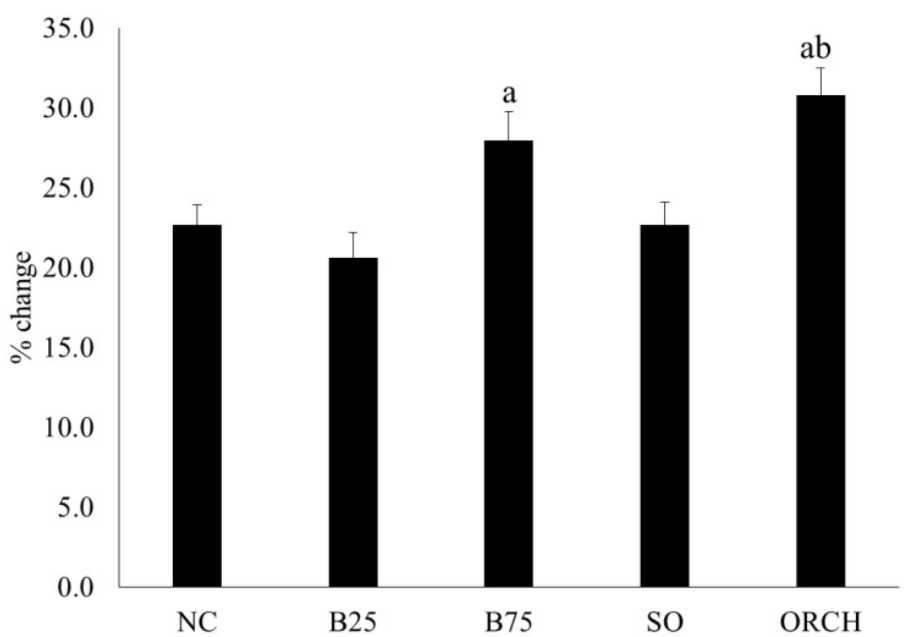

Figure 2. Percentage weight gain of the rats throughout the experiment. The data are shown as mean \pm standard error of the mean. Abbreviation: NC, normal group; B25, buserelin $25 \mu \mathrm{g} / \mathrm{kg}$ group; $\mathrm{B} 75$, buserelin $75 \mu \mathrm{g} / \mathrm{kg}$ group; ORCH, orchidectomy group; SO, sham orchidectomy group. Notes: aSignificant difference versus B25 group; bSignificant difference versus sham-operated group.

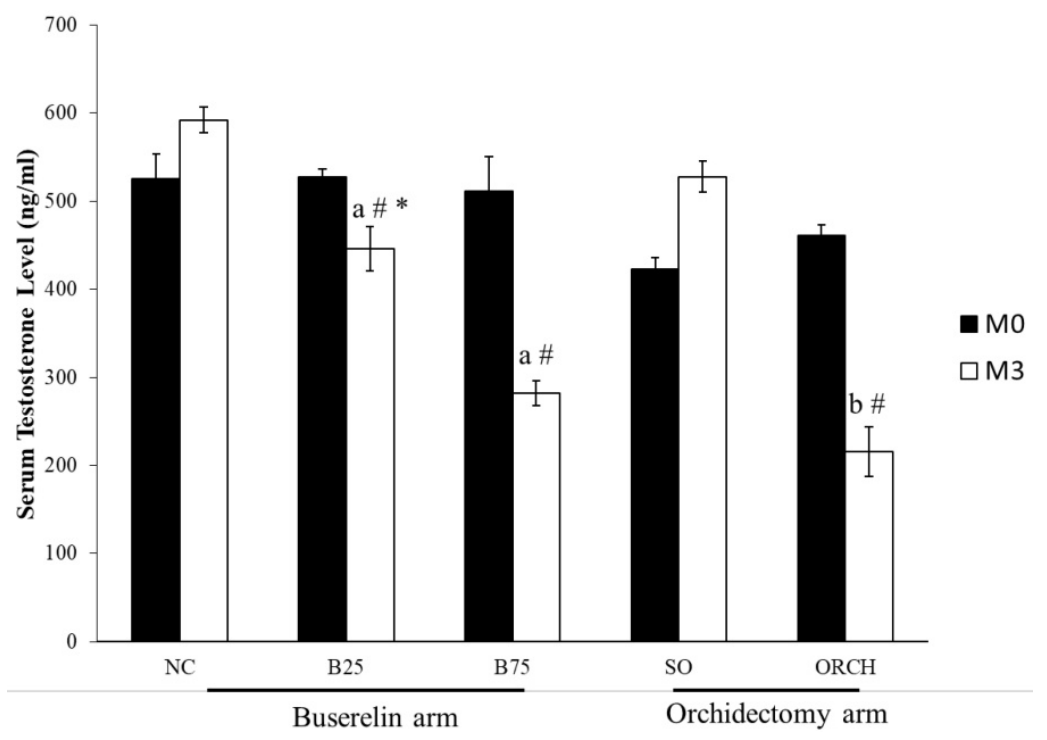

Figure 3. Serum testosterone of the rats before and after treatment. The data are shown as mean \pm standard error of the mean. Abbreviation: NC, normal group; B25, buserelin $25 \mu \mathrm{g} / \mathrm{kg}$ group; B75, buserelin $75 \mu \mathrm{g} / \mathrm{kg}$ group; ORCH, orchidectomy group; SO, sham orchidectomy group. Notes: aSignificant difference versus normal control; bSignificant difference versus sham-operated group; \#Significant difference versus baseline (month 0 ); *Significant difference versus orchidectomy.
(Figure 3).

X-ray micro-computed tomography revealed no significant difference in trabecular microstructural parameters among all the groups at baseline $(p>0.05)$. At month 3, there were significant decreases in bone volume, trabecular number and trabecular thickness, as well as a significant increase in trabecular separation for the all the groups compared with their respective baseline $(\mathrm{p}<0.05)$. In addition, the reduction in bone volume and trabecular number, and the increase in trabecular separation in the orchidectomized group were significantly more severe compared to the sham group after three months $(p<0.05)$. Similarly, the degenerative structural changes in trabecular bone were significantly more apparent in the B75 compared to the normal control after three months $(\mathrm{p}<0.05)$. Meanwhile, only trabecular separation increased significantly in the B25 group compared with the normal control $(p<0.05)$. There was no significant difference in trabecular indices between the orchidectomized and B75 group after three months $(p>0.05)$ (Figure 4).

There was no significant difference in the baseline cortical parameters among all the groups ( $>>0.05)$. At month 3 , there was a significant decrease in total area, cortical area and cortical thickness for the orchidectomized and B75 groups compared to their respective baseline group $(p<0.05)$. However, differences in cortical parameters were not statistically significant among all the groups $(p>0.05)$ (Figure 5).

Figure 6 showed the threedimensional (3D) reconstruction of trabecular and cortical bone at the proximal tibial metaphysis of male rats after three months of treatment. Trabecular bone was denser in the normal control group compared with the buserelin-treated groups, and in the sham-operated group compared with the orchidectomized group. Deterioration of trabecular bone was apparent for the orchidectomized, B75 and B25 group. Changes in cortical bone were not apparent among all the groups.

There was no significant difference in bone calcium content across all the groups after three months of the experiment $(p>0.05)$ (Figure 7). 
A

Bone volume of proximal tibia

घM0 aM1 口M2 口M3

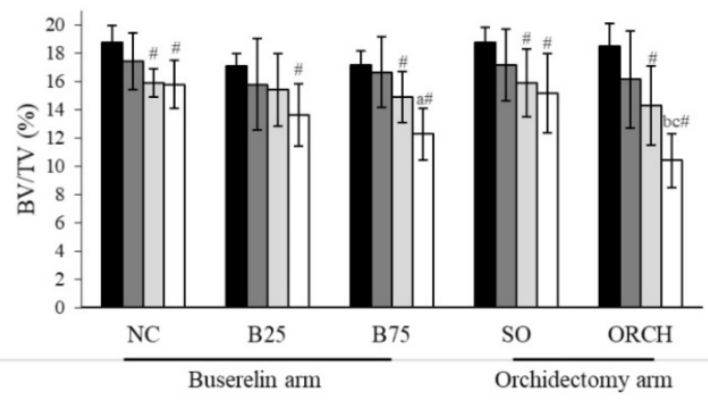

C

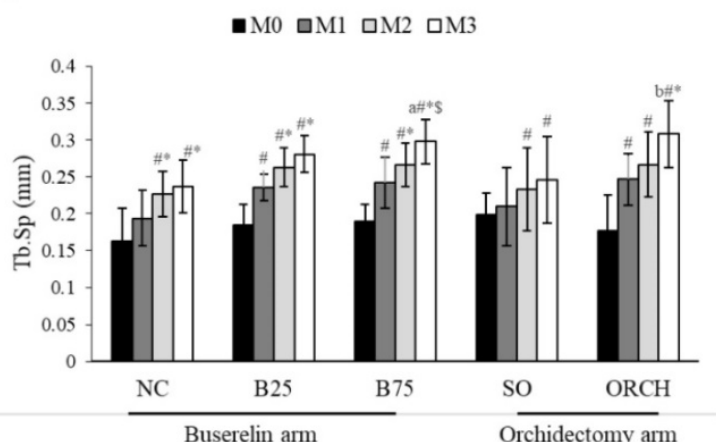

B

Trabecular number of proximal tibia

- M0 aM1 口M2 口M3

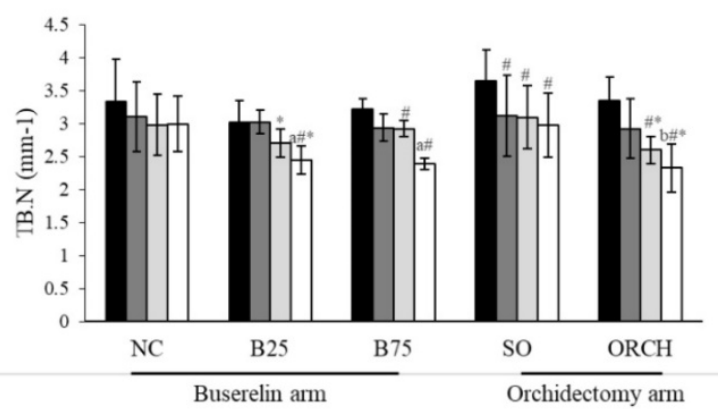

$\mathrm{D}$

Trabecular thickness of proximal tibia

घM0 aM1 口M2 口M3

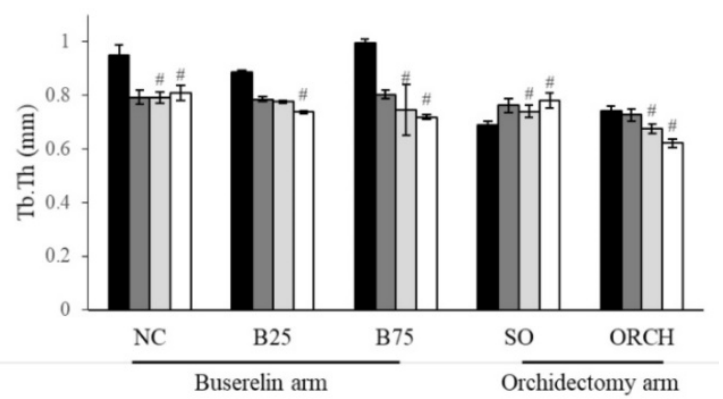

Figure 4. Trabecular bone indices at the proximal tibia of the rats evaluated using $\boldsymbol{\mu C T}$, i.e. bone volume/total volume (A), trabecular number (B), trabecular thickness (C) and trabecular separation (D). The data are shown as mean \pm standard error of the mean. Abbreviation: NC, normal group; B25, buserelin $25 \mu \mathrm{g} / \mathrm{kg}$ group; B75, buserelin $75 \mu \mathrm{g} / \mathrm{kg}$ group; ORCH, orchidectomy group; SO, sham orchidectomy group. Notes: aSignificant difference versus normal control; bSignificant difference versus sham-operated group; \#Significant difference versus baseline (month 0 ); *Significant difference versus month 1 ; \$Significant difference versus month 2

A Total area of proximal tibia

- M0 घM1 $\square \mathrm{M} 2 \square \mathrm{M} 3$

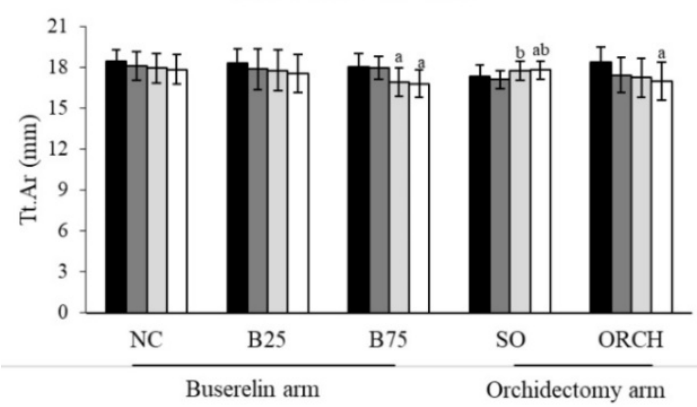

Cortical thickness of proximal tibia

C

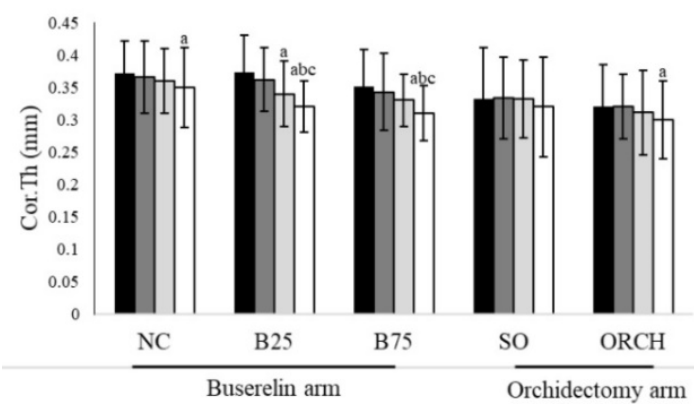

B

Cortical area of proximal tibia

- M0 aM1 $\mathrm{aM} 2 \mathrm{aM} 3$

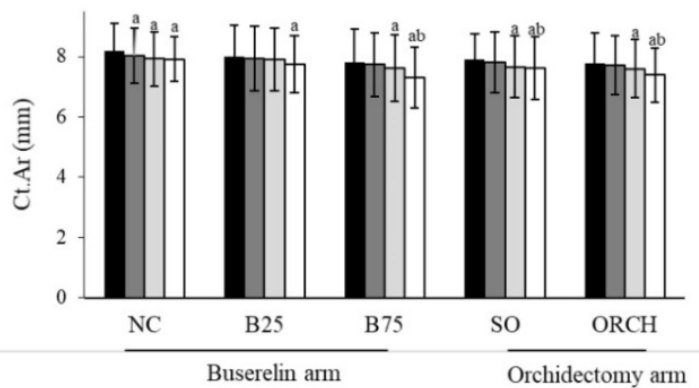

D

Cortical area over total area of proximal tibia

- M0 घM1 $\square \mathrm{M} 2 \square \mathrm{M} 3$

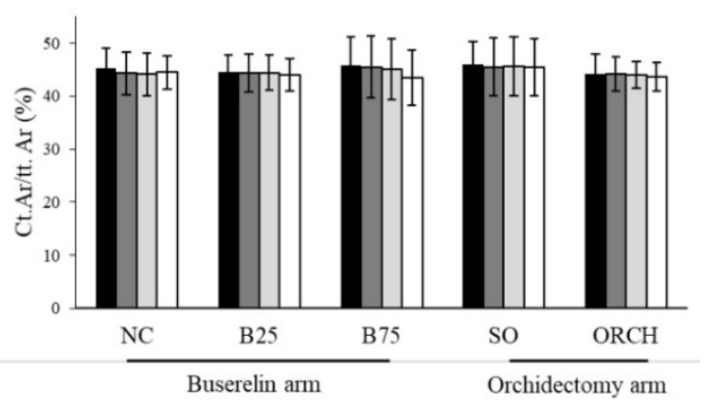

Figure 5. Cortical structural indices at the proximal tibia of rats evaluated using $\mu$ CT ie. Total area (A), cortical area (B), cortical thickness (C) and cortical area over total area (D). The data are shown as mean \pm standard error of the mean. Abbreviation: NC, normal group; B25, buserelin $25 \mu g / k g$ groups; B75, buserelin $75 \mu \mathrm{g} / \mathrm{kg}$ groups; ORCH, orchidectomy group; SO, sham orchidectomy group. Notes: aSignificant difference versus baseline (month 0); bSignificant difference versus month 1; cSignificant difference versus month 2. 
Buserelin at $25 \mu \mathrm{g} / \mathrm{kg}$ decreased displacement and strain of the femur significantly compared to the normal control after three months $(\mathrm{p}<0.05)$. Orchide-

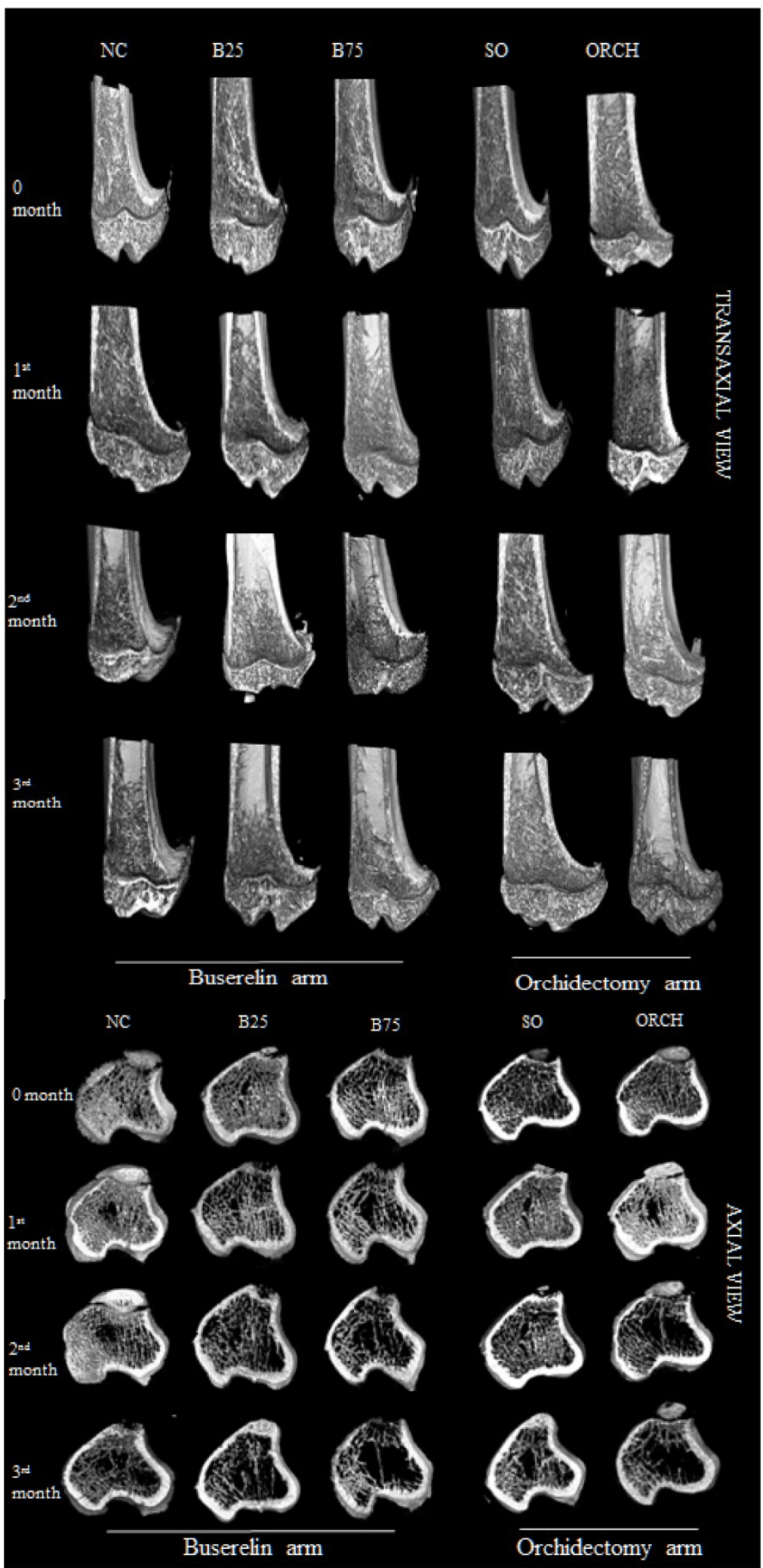

Figure 6. Three-dimensional micro-CT images of the trabecular microstructure of distal tibia metaphysis at the transaxial and axial view. Abbreviation: NC, normal group;

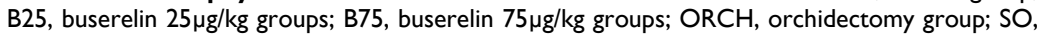
sham orchidectomy group. ctomy did not affect these two indices significantly compared with the sham group $(p>0.05)$. Buserelin at $75 \mu \mathrm{g} / \mathrm{kg}$ did not affect any biomechanical strength indices $(p>0.05)$. Both orchidectomy and buserelin injections did not alter load and stress of the femur significantly after three months $(p>0.05)$ (Figure 8).

\section{Discussion}

In the present study, testosterone deficiency was successfully induced by buserelin and orchidectomy after three months. Both buserelin-treated and orchidectomized rats showed degenerative changes in the microstructure at the proximal tibia after three months. Testosterone deprivation induced by buserelin also caused significant changes in displacement and strain, but did not affect bone calcium content level. Skeletal effects of buserelin were similar with orchidectomy except in bone mechanical strength, whereby the changes caused by buserelin were more apparent. The studies of buserelin-induced osteoporosis model in male rats are limited. Therefore, the comparison was made with studies using other models of bone loss in the following discussion.

Circulating testosterone level was determined in this study to represent the androgen status because it is the most prevalent androgen in men [5]. Both orchidectomy and buserelin injection decreased testosterone level in rats as expected. The degree of testosterone suppression induced by orchidectomy and buserelin at $75 \mathrm{mg} / \mathrm{kg}$ after three months was similar. Other studies showed that orchidectomy resulted in $80 \%$ reduction in serum testosterone in male rats after two months post-surgery [22]. The remaining circulating testosterone may originate from the peripheral production of the adrenal gland [23]. Orchidectomy was similar to primary hypogonadism in human, whereby the reason for testosterone deficiency lies with the testis. In contrast, buserelin-induced testosterone deficiency is a model of secondary hypogonadism. It is caused by disruption of the hypothalamic-pituitary-gonadal axis. It is experienced by male prostate cancer 
patients using buserelin to retard the progression of cancer. However, the decrease in testosterone level will cause other side effects, including osteoporosis [24].

Buserelin and orchidectomy resulted in a comparable deterioration in trabecular bone in this study, marked by reduced bone volume and trabecular number, and increased trabecular separation after three months. Similar studies by Tobias et al. found that buserelin caused a progressive decline in trabecular bone volume at the proximal tibial metaphysis of female rats after three months [25]. Alterations in trabecular structure in male rats due to orchidectomy, such as decreased trabecular number and thickness, and increased trabecular separation have been well characterised by previous researchers. [26, 27]. The trabecular indices between orchidectomized and buserelin-treated rats were similar because their circulating testosterone was similar. In addition, we hypothesize that with the reduction in the trabecular number and the widening of the trabecular separation, there would be a compensatory trabecular thickening. As the result, the trabecular thickness was not changed by orchidectomy and buserelin. Both orchidectomy and buserelin had no effects on cortical bone of the rats in this study. The microstructure of cortical bone is denser and more rigid, therefore offering lesser surface to volume ratio for the interaction with endogenous factors compared to trabecular bone. This might be the reason cortical bone is not responsive to androgen deficiency. A previous study also showed that orchidectomy only affected the composition and quality of the cortical bone to a minor extent even after six months post-surgery [28].

Calcium plays an integral part in bone

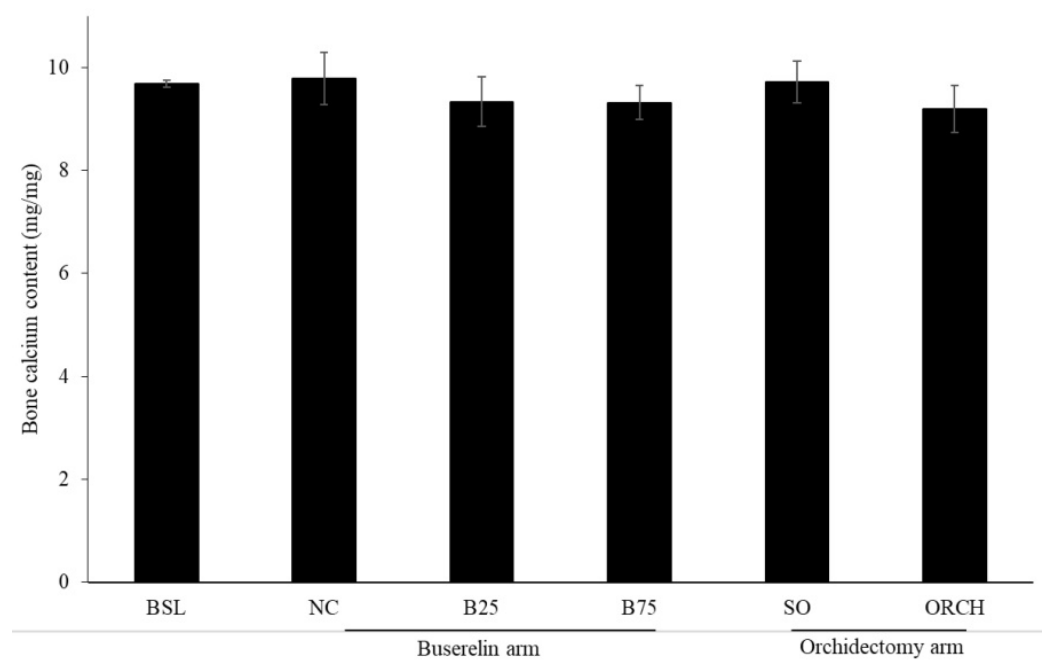

Figure 7. Post-treatment bone calcium level in rats. The data are shown as mean \pm standard error of the mean. Abbreviation: NC, normal group; B25, buserelin $25 \mu \mathrm{g} / \mathrm{kg}$ groups; B75, buserelin $75 \mu \mathrm{g} / \mathrm{kg}$ groups; ORCH, orchidectomy group; SO, sham orchidectomy group. metabolism and remodelling. Calcium in the form of hydroxyapatite is the predominant mineral in the bone. The combination of calcium with other minerals will form a hard crystal, which gives the structure and strength to the bone [29]. Previous studies found that bone calcium content in orchidectomized rats was lower compared to sham-operated animals after eight months post-treatment, probably due to the mobilization of calcium from the bone to the circulation[30]. However, our study showed the calcium content in both buserelin-treated rats and orchidectomized rats did not decrease significantly. This could be due to the relatively short experimental period (three months). A previous study by Chin et al. also found that the bone calcium level was not significantly altered two months post-orchidectomy [31].

Material and geometric properties are the main contributors of skeletal biomechanical strength [32]. The material properties comprise of load, displacement and elasticity. They are also known as the extrinsic parameters that reflect the whole bone. Maximum load, which is the maximum amount of force needed to break the bone, indicates the whole bone strength. Displacement, which is the length of deformation that the bone can sustain before failing, measures the bone ductility [33]. Geometric properties of the bone, also known as intrinsic parameters, include strain, stress and Young's modulus. Stress is the strength of the bone tissue under a given loading condition, whereas strain represents ductility of the bone [34]. The whole bone biomechanical test can be performed either in bending, compression or torsion loading settings [35]. Bending test was used in this study because of the small and irregular shape of the femur. Orchidectomy did not result in significant change in all biomechanical parameters. This was consistent with the study by Chin et al. and Yarrow et al., which demonstrated that orchidectomy did not affect biomechanical parameters in male rats [26, 31]. Surprisingly, rats treated with buserelin at 25 $\mu \mathrm{g} / \mathrm{kg}$ showed significant decreased displacement and strain compared with the normal control. This indicated that the bones of buserelin-treated rats were less ductile and broke easily. However, the results were not consistent because buserelin at $75 \mu \mathrm{g} / \mathrm{kg}$ did not cause any changes to femoral biomechanical strength parameters. 

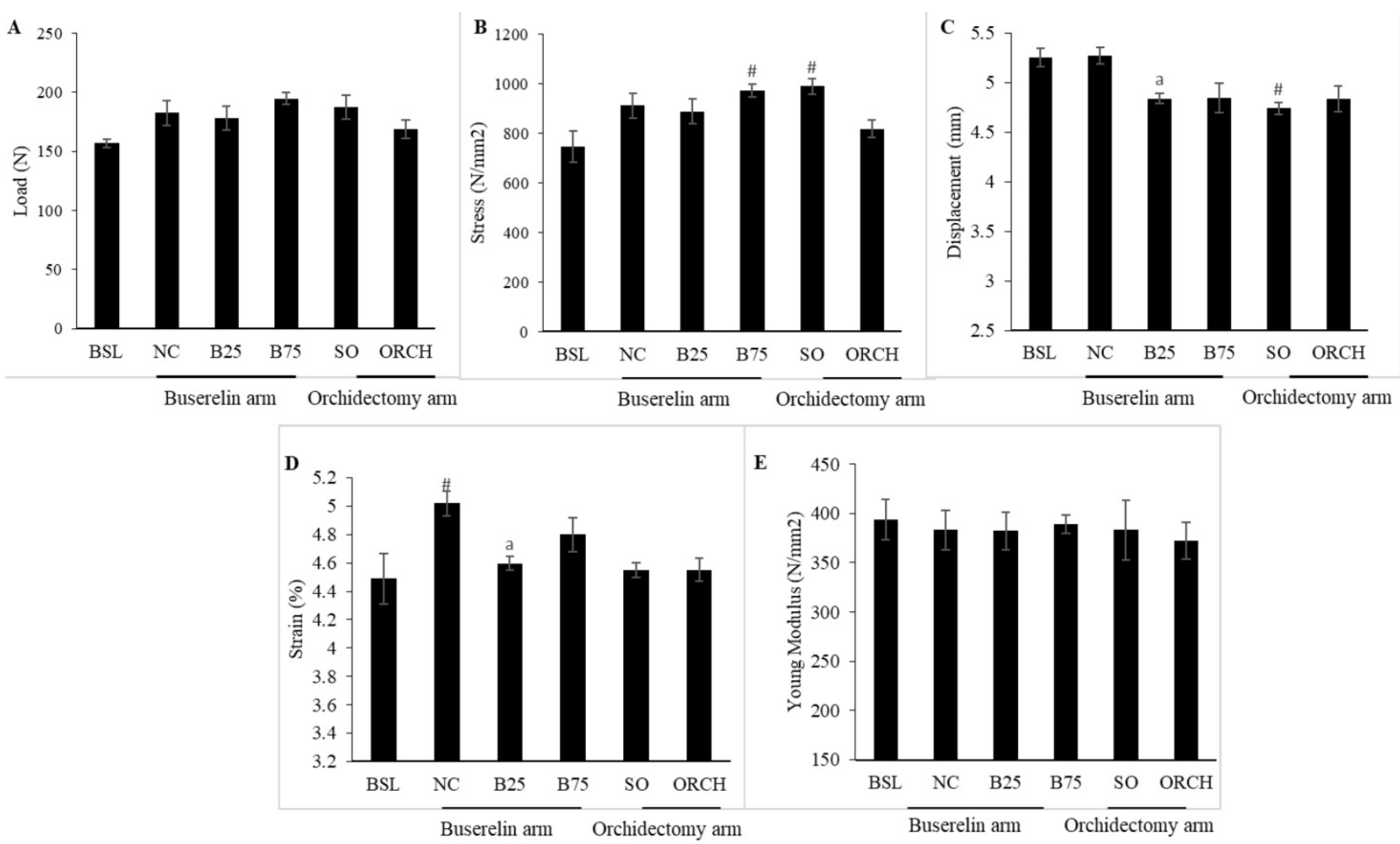

Figure 8. Post-treatment biomechanical strength parameters of the left femur, i.e. load (A), stress (B), displacement (C), strain (D), and Young Modulus (E). The data are shown as mean \pm standard error of the mean. Abbreviation: Abbreviation: NC, normal group; B25, buserelin 25 $\mu \mathrm{g} / \mathrm{kg}$ group; B75, buserelin $75 \mu \mathrm{g} / \mathrm{kg}$ group; ORCH orchidectomy group; SO, sham orchidectomy group. Notes: aSignificant difference versus normal control; \#Significant versus baseline group

To our surprise, the skeletal effects of buserelin at $25 \mu \mathrm{g} / \mathrm{kg}$ seemed to be more severe than buserelin at $75 \mu \mathrm{g} / \mathrm{kg}$ and orchidectomy. We hypothesized that both buserelin treatment and orchidectomy were detrimental to the bone. At the same time, buserelin at $75 \mu \mathrm{g} / \mathrm{kg}$ and orchidectomy induced significant weight gain in rats compared to buserelin at $25 \mu \mathrm{g} / \mathrm{kg}$, probably due to increased adiposity induced by severe testosterone ablation. The weight gain caused compensatory mechanism that strengthened the bone to support the extra mechanical loading. This translated to a better biomechanical strength for rats in B75 and orchidectomized group. However, this speculation needs to be validated in further study.

Several limitations need to be addressed in this study. The study duration was three months, which might be insufficient to cause severe deterioration in bone biomechanical strength and bone calcium in male rats. Better results might be achieved by prolonging the study period. Biomechanical strength test and microarchitecture assessment were conducted on different bone segments. Therefore, they might not correlate well with each other. We did not perform bone histomorphometry to assess the mineralization process and changes in bone cells, as well as bone turnover markers to assess the bone remodelling process. Nevertheless, this is the first study that examined the skeletal effects of buserelin in a rat model of male osteoporosis. The present study characterised the skeletal changes in a buserelin-induced secondary hypogonadism animal model. This model mimics osteoporosis in male patients suffering from secondary hypogonadism, like patients receiving $\mathrm{GnRH}$ agonist for prostate cancer. It can be used to understand the disease process and as a model to search for the treatment of osteoporosis induced by secondary hypogonadism.

\section{Conclusion}

In conclusion, buserelin can cause osteoporosis due to testosterone deficiency in male rats. The skeletal effects of buserelin are comparable to orchidectomy in male rats. However, adjustment to the duration of buserelin treatment may be required so that effects on bone biomechanical strength and calcium content can be demonstrated. Further studies on bone histomorphometry will help to demonstrate the effects of buserelin on mineralization process and bone cell ratio.

\section{Abbreviations}

GnRH agonist: Gonadotropin-releasing hormone; micro-CT: micro-computed tomography; 3D: three dimensional; FSH: follicle-stimulating hormone; LH: luteinizing hormone. 


\section{Acknowledgements}

We thank Universiti Kebangsaan Malaysia for funding this study via Fundamental Research Grant GGPM-2015-036 and FF-2016-430. We also thank Mr Azlan Mohd Arlamsyah, Mr Muhamad Arizi Aziz and $\mathrm{Mr}$ Mohd Mustazil Mohd Noor from the Department of Pharmacology for their technical assistance.

\section{Competing Interests}

The authors have declared that no competing interest exists.

\section{References}

1. Riggs BL, Melton LJr. The worldwide problem of osteoporosis: insights afforded by epidemiology. Bone. 1995; 17: S505-S11.

2. Kanis JA, Melton LJ, Christiansen C, Johnston CC, Khaltaev N. The diagnosis of osteoporosis. J Bone Miner Res. 1994; 9: 1137-41.

3. Si L, Winzenberg $\mathrm{T}$, Jiang $\mathrm{Q}$, Chen $\mathrm{M}$, Palmer A. Projection of osteoporosis-related fractures and costs in China: 2010-2050. Osteoporosis International. 2015; 26: 1929-37.

4. Budhia S, Mikyas Y, Tang M, Badamgarav E. Osteoporotic Fractures. Pharmacoeconomics. 2012; 30: 147-70.

5. Chin K-Y, Ima-Nirwana S. Sex steroids and bone health status in men. International journal of endocrinology. 2012; 2012.

6. Organization WH. The Burden of Musculoskeletal Diseases at the Start of the Millennium: Technical Report Series Report of a WHO Scientific Report: World Health Organization. 2003.

7. Bliuc D, Alarkawi D, Nguyen TV, Eisman JA, Center JR. Risk of subsequent fractures and mortality in elderly women and men with fragility fractures with and without osteoporotic bone density: the Dubbo Osteoporosis Epidemiology Study. Journal of bone and mineral research. 2015; 30: 637-46.

8. Mohamad N-V, Soelaiman I-N, Chin K-Y. A concise review of testosterone and bone health. Clin Interv Aging. 2016; 11: 1317.

9. Tajar A, Forti G, O'neill TW, Lee DM, Silman AJ, Finn JD, et al. Characteristics of secondary, primary, and compensated hypogonadism in aging men: evidence from the European Male Ageing Study. The Journal of Clinical Endocrinology \& Metabolism. 2010; 95: 1810-8.

10. Khera M, Broderick GA, Carson CC, Dobs AS, Faraday MM, Goldstein I, et al. Adult-onset hypogonadism. Mayo Clinic Proceedings: Elsevier; 2016; 91(7): 908-26.

11. Raisz LG. Osteoporosis: current approaches and future prospects in diagnosis, pathogenesis, and management. J Bone Miner Res. 1999; 17: 79-89.

12. Blouin S, Libouban H, Moreau MF, Chappard D. Orchidectomy models of osteoporosis. Osteoporosis: Methods and Protocols. 2008: 125-34.

13. Chin K-Y, Ima-Nirwana S. The effects of orchidectomy and supraphysiological testosterone administration on trabecular bone structure and gene expression in rats. The Aging Male. 2015; 18: 60-6.

14. Gaumet-Meunier N, Coxam V, Robins S, Pastoureau P, Pointillart A, Davicco $\mathrm{M}-\mathrm{J}$, et al. Gonadal steroids and bone metabolism in young castrated male rats. Calcif Tissue Int. 2000; 66: 470-5.

15. Fraietta R, Zylberstejn DS, Esteves SC. Hypogonadotropic hypogonadism revisited. Clinics. 2013; 68: 81-8.

16. Magon N. Gonadotropin releasing hormone agonists: Expanding vistas. Indian J Endocrinol Metab. 2011; 15: 261.

17. [Internet] DrugBank. Buserelin. https://www.drugbank.ca/drugs/DB06719. Last Update: 06/11/2017. Accessed: 08/11/2017

18. Brogden RN, Buckley MM, Ward A. Buserelin. A review of its pharmacodynamic and pharmacokinetic properties, and clinical profile. Drugs. 1990; 39: 399-437

19. Mohamad NV, Soelaiman IN, Chin KY. Effect of Androgen Deprivation Therapy (ADT) on Bone Health Status in Men with Prostate Cancer. Endocr Metab Immune Disord Drug Targets. 2017; in press.

20. Goulding A, Gold E. Buserelin-mediated osteoporosis: Effects of restoring estrogen on bone resorption and whole body calcium content in the rat. Calcif Tissue Int. 1990; 46: 14-9.

21. Sakamoto S, Sassa S, Kudo H, Suzuki S, Mitamura T, Shinoda H. Preventive effects of a herbal medicine on bone loss in rats treated with a $\mathrm{GnRH}$ agonist. Eur J Endocrinol. 2000; 143: 139-42.

22. Erben RG, Eberle J, Stahr K, Goldberg M. Androgen deficiency induces high turnover osteopenia in aged male rats: a sequential histomorphometric study. J Bone Miner Res. 2000; 15: 1085-98.

23. Nishiyama T. Serum testosterone levels after medical or surgical androgen deprivation: A comprehensive review of the literature. Urologic Oncology: Seminars and Original Investigations: Elsevier. 2014; 32(1e):17-38. e28.
24. Lassemillante A-CM, Doi SA, Hooper JD, Prins JB, Wright OR. Prevalence of osteoporosis in prostate cancer survivors: a meta-analysis. Springer. 2014.

25. Tobias J, Chambers T, Gallagher A. Effect of administration and subsequent cessation of buserelin on cancellous bone of female rats. J Bone Miner Res. 1994; 9: 1919-25.

26. Yarrow JF, Conover CF, Purandare AV, Bhakta AM, Zheng N, Conrad B, et al. Supraphysiological testosterone enanthate administration prevents bone loss and augments bone strength in gonadectomized male and female rats. Am J Physiol Endocrinol Metab. 2008; 295: E1213-E22.

27. Libouban H, Blouin S, Moreau M-F, Baslé MF, Audran M, Chappard D. Effects of risedronate in a rat model of osteopenia due to orchidectomy and disuse: densitometric, histomorphometric and microtomographic studies. Micron. 2008; 39: 998-1007.

28. Danielsen CC, Mosekilde L, Andreassen TT. Long-term effect of orchidectomy on cortical bone from rat femur: bone mass and mechanical properties. Calcified tissue international. 1992; 50: 169-74.

29. Zhu K, Prince RL. Calcium and bone. Clinical biochemistry. 2012; 45: 936-42.

30. Ima-Nirwana S, Kiftiah A, Zainal A, Norazlina M, Gapor M, Khalid B. Palm vitamin $\mathrm{E}$ prevents osteoporosis in orchidectomized growing male rats. Nat Prod Sci. 2000; 6: 155-60.

31. Chin K-Y, Gengatharan D, Mohd Nasru FS, Khairussam RA, Ern SLH, Aminuddin SAW, et al. The Effects of Annatto Tocotrienol on Bone Biomechanical Strength and Bone Calcium Content in an Animal Model of Osteoporosis Due to Testosterone Deficiency. Nutrients. 2016; 8: 808

32. Winter $\mathrm{W}$. Bone strength in pure bending: Bearing of geometric and material properties. Stud Health Technol Inform. 2008; 133: 230.

33. Hernandez C, Keaveny T. A biomechanical perspective on bone quality. Bone. 2006; 39: 1173-81.

34. Keaveny TM, Wachtel EF, Kopperdahl DL. Mechanical behavior of human trabecular bone after overloading. J Orthop Res. 1999; 17: 346-53.

35. Cole JH, van der Meulen MC. Whole bone mechanics and bone quality. Clin Orthop Relat Res. 2011; 469: 2139-49. 